\title{
Borradores e impresos unamunianos. Variantes de autor y "de copia" en Del sentimiento trágico de la vida (con unas calas intermedias en la tradición de La Venda, cuento y drama $)^{1}$
}

\section{Paolo Tanganelli}

\section{Universidad de Ferrara}

Título: Borradores e impresos unamunianos. Variantes de autor y "de copia" en Del sentimiento trágico de la vida (con unas calas intermedias en la tradición de La Venda, cuento y drama).

Resumen: El artículo pone de manifiesto las diferencias entre un aparato crítico en una edición neolachmanniana y un aparato de variantes para la llamada "Filología de autor". Luego ofrece ejemplos de edición filológica tanto para el relato La venda como para el drama homónimo. Y finalmente examina el autógrafo acéfalo de Del sentimiento trágico de la vida, explicando cómo este manuscrito puede utilizarse para corregir los errores que deturpan la tradición impresa de dicha obra.

Palabras clave: Filología. Aparato crítico. Unamuno. La venda. Del sentimiento trágico de la vida.

Fecha de recepción: 16/3/2014.

Fecha de aceptación: 3/5/2014.
Title: Unamunian Drafts and Printed Editions. Author's Variants and Variants of Copy in Del sentimiento trágico de la vidaa (with some Intermediate Insights into the Tradition of La Venda, Short Story and Play)

Abstract: The article highlights the differences between a critical apparatus in a Neolachmannian edition and an apparatus of variants according to the Filologia d'autore. Then, it shows some examples of philological edition both for the story La venda and for the homonymous drama. Finally, it examines the acephalous autograph of Del sentimiento trágico de la vida and explains how this manuscript can be used in order to amend the errors that corrupt the printed tradition of this work.

Key words: Philology. Critical apparatus. Unamuno. La venda. Del sentimiento trágico de la vida.

Date of Receipt: 16/3/2014.

Date of Approval: 3/5/2014.

1 A Giuseppe Mazzocchi. 


\section{MÉtodos Y APARATOS}

El trabajo del filólogo de autor debería ser bastante más llevadero que el del crítico textual, puesto que trabaja con originales y no debe "reconstruir un ente desaparecido, sino tan solo dar cuenta de lo existente" ${ }^{2}$; sin embargo, las insidias que debe sortear no son menos peligrosas, y crecen de manera exponencial cuando se enfrenta a obras en redacciones múltiples, en su empeńo de representar ante el lector su reconstrucción de la evolución textual.

Por supuesto, ambos métodos -la filología de autor y la ecdótica neolachmanniana-comparten una misma pretensión primordial: la de fijar un texto a partir de una determinada hipótesis, capaz de sistematizar (o sea, de conectar en un sistema coherente) todos los testimonios conservados de una obra; pero, para lograr este objetivo común (la constitutio textus), nos brindan unos instrumentos complementarios y sustancialmente diferentes, a pesar del mismo nombre que los identifica (razón por la cual se puede crear cierta confusión sobre sus respectivas funciones).

En efecto, la palabra aparato sirve para indicar tanto la sección que reúne la varia lectio o "fenomenología de la copia" en una edición crítica, como para denominar la representación de las variantes de autor en el caso de un texto del que se conserven varias redacciones o un único autógrafo in fieri con correcciones. Sin embargo, no debe engañarnos la centralidad que ambos métodos otorgan a ese dispositivo tan poderoso cuanto, a menudo, de penosa lectura; y para evitar malentendidos, como decía, huelga remachar desde el primer momento que no se trata precisamente del mismo objeto. Porque, a pesar de la identidad onomástica, el aparato desempeña tareas diversas y muda conforme cambian las tradiciones a las que se aplica: originales por un lado, copias por otro.

En el método del error significativo el aparato crítico constituye el indispensable trait-d'union entre las dos hipótesis especulares que se han formulado: por un lado, el texto crítico (es decir, la hipótesis de recons-

2 "Se invece di un'opera possediamo l'originale [...], la situazione cambia radicalmente perché non si tratta più di ricostruire un'entità scomparsa, ma di dar conto dell'esistente, con tutta la cura dovuta a ciò che senza dubbio dipende dalla volontà dell'autore", Alfredo Stussi, "Filologia d'autore", Fondamenti di critica testuale, Bologna, il Mulino, 2006, pp. 167-179 (p. 168). 
trucción del original perdido ${ }^{3}$ ); por otro, el árbol genealógico que jerarquiza los testimonios supervivientes (y que nunca debe confundirse con el árbol real de todos los testimonios que existieron en su día ${ }^{4}$ ); más exactamente, el aparato crítico neolachmanniano constituye la base documental de dos hipótesis que guardan una estrecha correlación: el estema y el texto crítico. Por eso la lectura del aparato crítico -sé bien que los lectores de esta clase corremos peligro de extinción- requiere una mirada 'estrábica', que debe desplegarse siguiendo una doble dirección: hacia el texto reconstruido y, a la vez, hacia el estema conjeturado. Hacia el texto para valorar las decisiones del editor respecto a cada lección concreta, sobre todo en los casos de recensio abierta en los que resulta forzoso aplicar criterios internos de elección (o sea, no mecánicos), como el usus scribendi o la lectio difficilior. Y hacia el stemma codicum para comprobar en todo momento su validez, ya que el estema propuesto debería demostrarse como la hipótesis más económica de sistematización de los datos (ante todo, los llamados errores guía) que brinda la varia lectio.

El panorama es muy diferente cuando el editor se ocupa de "uno o más manuscritos autógrafos (o idiógrafos), o más bien [de] impresiones controladas por el mismo autor" ${ }^{5}$. Y esto porque la filología de autor, además de la fijación textual (que, por supuesto, no siempre debe ser forzosamente del último estadio de elaboración de una obra), apunta, como acabo de recordar, hacia otro blanco no menos ambicioso e importante, para el cual se sirve precisamente del aparato: debe reconstruir e ilustrar, en la medida de lo posible, el proceso de revisión y corrección llevado a cabo por el escritor.

Es cierto que los primeros aparatos genéticos o evolutivos de la filología de autor se inspiraban en los tradicionales aparatos críticos neolachman-

3 El texto crítico reconstruido es más verdadero que cualquier documento, como explica Gianfranco Contini, Filologia, ed. Lino Leonardi, Bologna, il Mulino, 2014, p. 28; sobre las implicaciones de este principio, puede verse Lino Leonardi, "Il testo come ipotesi (critica del manoscritto-base)", Medioevo romanzo, 35, 2011, pp. 5-34.

4 Véase Paolo Trovato, Everything you Always Wanted to Know about Lachmann's Method. A Non-Standard Handbook of Genealogical Textual Criticism in the Age of Post-Structuralism, Cladistics, and Copy-Text, Padova, Libreriauniversitaria.it, 2014, pp. 85-94.

5 Alfredo Stussi, "Filologia d'autore", Introduzione agli studi di filologia italiana, Bologna, il Mulino, 2011, pp. 147-246 (p. 147). 
nianos, al pretender fotografiar cada variante individual de los originales desligándola de las diferentes fases del proceso de escritura y corrección autorial. No obstante, a partir sobre todo de la edición que Dante Isella publicó en 1983 del Racconto italiano di ignoto del Novecento, los aparatos de variantes autoriales han tomado conciencia de su diferente función, y se han vuelto cada vez más sistémicos y diacrónicos ${ }^{6}$ : es decir, se ha pasado a fabricar aparatos cada vez más dinámicos, que privilegian la interpretación (de los estratos y de las fases del proceso de creación) respecto a otros detalles relativos a la colocación física de las variantes individuales o a sus características gráficas ${ }^{7}$. Como observan Italia y Raboni, cada aparato genético "no es una fotografía del texto [sc. de los documentos que transmiten el texto], sino una hipótesis del estudioso acerca de los modos y de los tiempos de su elaboración". Esto es lo esencial, al menos a mi juicio: el aparato crítico tradicional es la base documental de dos hipótesis (estema y texto crítico), pero no es él mismo una hipótesis interpretativa como, en mayor o menor medida, lo son los aparatos genéticos y evolutivos que ilustran y 'racionalizan' la fenomenología del original'.

Desde luego, con cierta frecuencia se pueden dar situaciones híbridas donde el filólogo tiene a disposición uno o más originales, pero, a la vez, debe tener muy en cuenta los apógrafos, como sucede con el comentario del Cántico espiritual de Juan de la Cruz, del que ha sobrevivido una copia glosada y corregida parcialmente por el autor (el ms. $\boldsymbol{S}$ de Sanlúcar de Barrameda) y otros códices no idiógrafos que permiten enmendar algunos errores de dicho testimonio de los que no se percató el místico de

6 Véase Paola Italia y Giulia Raboni, Che cos'è la filologia d'autore, Roma, Carocci, 2010, p. 59.

7 Por supuesto, esta evolución de los aparatos autoriales no ha sido autotélica; más bien la ha impulsado la necesidad de enfrentarse a borradores y tradiciones cada vez más complicados de representar, como los que, en el ámbito del italianismo, ofrecían -a Dante Isella y a sus discípulos- el corpus de Gadda o el Fermo e Lucia de Manzoni.

8 Paola Italia y Giulia Raboni, op. cit., p. 45.

9 La racionalización de los borradores empieza con la elemental distinción que introduce Isella entre correcciones, variantes alternativas y glosas (Paola Italia y Giulia Raboni, op. cit., p. 61); el aparato, obviamente, solo interpreta y racionaliza las fases de corrección. 
Fontiveros ${ }^{10}$. Lo más importante, ante una tradición híbrida, es separar las variantes de autor de las variantes de copia, utilizando, a la hora de confeccionar una edición filológica, dos modalidades o, mejor aún, dos aparatos diferentes para representar cada especie de variante. Situaciones de este tipo se presentan a menudo cuando se dispone tanto de autógrafos como de versiones impresas de una obra, porque, aunque un escritor haya controlado las galeradas, es muy fácil que en cada reimpresión se inserten variantes de autor y a la vez se deslicen nuevos errores de composición del tipógrafo $^{11}$ (el cual se equivoca como cualquier copista, si bien es cierto que los errores de los textos impresos poseen ciertas peculiaridades ${ }^{12}$ ).

En este artículo me ocuparé de la tradición híbrida o mixta del más famoso ensayo filosófico de Unamuno; pero antes de abordar dicha cuestión, voy a rememorar, con otro par de ejemplos unamunianos, la obvia

10 San Juan de la Cruz, Cántico espiritual y poesía completa, ed. María Jesús Mancho Duque y Paola Elia, Barcelona, Crítica, 2002 [Historia del texto, pp. CXIX-CLII y edición crítica de Paola Elia].

11 Ya Ferruccio Cecco, en su edición de los Malavoglia de Verga, había separado las variantes atribuibles al tipógrafo de las variantes de autor. Véase Paola Italia y Giulia Raboni, op. cit., p. 32.

12 La bibliografía sobre los errores en la imprenta manual antigua es muy dilatada. En ámbito hispánico la discusión teórica se ha centrado sobre la obra maestra cervantina, con dos interlocutores principales: por un lado, Francisco Rico, El texto del "Quijote": preliminares a una ecdótica del Siglo de Oro, Barcelona / Valladolid, Destino / Centro para la Edición de los Clásicos Españoles y Universidad de Valladolid, 2005; por otro, Florencio Sevilla Arroyo, con varios artículos entre los cuales cabe recordar: "El texto definitivo del «Quijote», según Cervantes", Edad de oro, 25 (2006), pp. 581-606; " "Famoso (y valiente) hidalgo»: sobre conjeturas y deturpaciones textuales", Anales cervantinos, 39 (2007), pp. 53-77; "“Cuenta del original» y remedios de cajista en la "princeps» del primer "Quijote»", Cervantes: Bulletin of the Cervantes Society of America, 28-1 (2008), pp. 53-82; "La "cuenta del original" en el primer Quijote: consecuencias textuales", Anuario de estudios cervantinos, 4 (2008), pp. 69-104; "La intervención de la imprenta en el texto del tercer "Quijote» de Cuesta (1608)", Edad de oro, 28 (2009), pp. 359-400. Otras contribuciones significativas son: Francisco Rico, Pablo Andrés y Sonia Garza (eds.), Imprenta y crítica textual en el Siglo de Oro, Valladolid, Centro para la Edición de los Clásicos Españoles / Universidad de Valladolid, 2000; y Begoña Rodríguez Rodríguez, Del original de imprenta al libro impreso antiguo, Madrid, Ollero y Ramos, 2014. En torno a los errores en textos italianos del siglo XX, resulta muy útil Paola Italia, Editing Novecento, Roma, Salerno Editrice, 2013, pp. 20-27. 
(mas muy descuidada) necesidad de llevar a cabo siempre una seria recensio y collatio de las diferentes versiones de cada obra.

\section{REDACCIONES MÚLTIPLES Y MISERIAS DE LA FILOLOGÍA UNAMUNIANA}

Hasta ahora los filólogos unamunianos se han preocupado principalmente de rescatar textos perdidos en la prensa periódica o inéditos pertenecientes a la categoría de las obras únicas in fieri, mientras que solo en contadas ocasiones han realizado las forzosas pesquisas para descubrir la existencia de diferentes redacciones de una misma obra y luego determinar la secuencia de las reescrituras.

Las Obras Completas preparadas por García Blanco ${ }^{13}$, cuya primera edicición se empezó a publicar en 1958, tienen tantos méritos como defectos. Impulsaron el estudio del maestro vasco en unos tiempos no muy propicios (recuérdese que el año anterior habían acabado en el índice de los libros prohibidos Del sentimiento trágico de la vida y la Agonía del cristianismo); pero, por lo general, ofrecieron textos fijados de forma bastante arbitraria. Lo más grave, no obstante, es la negligencia de la mayoría de las ediciones sucesivas, incluyendo las Obras Completas preparadas bajo la dirección de Senabre ${ }^{14}$, ya que casi nadie se ha atrevido a verificar los concretos resultados del esfuerzo titánico de García Blanco.

En realidad, la recensio del primer editor puede tacharse a menudo de insuficiente. Por ejemplo, en el caso de uno de los cuentos más estudiados de Unamuno, $L a$ venda, se conoce solo la versión que apareció en los $L u$ nes de "El Imparcial" el 22 de enero de 1900. Esta, sin embargo, no es la única redacción supérstite del relato. En la Casa-Museo de Salamanca se guarda un autógrafo (sign. CMU, 63/5) que, a primera vista, tiene toda la pinta de ser una copia del texto publicado, ya que Unamuno mismo indicó el nombre de la revista y la fecha de publicación. No se trata, sin

13 Miguel de Unamuno, Obras completas, ed. Manuel García Blanco, Madrid, Afrodisio Aguado, 16 vols., 1958-1964; y Miguel de Unamuno, Obras completas, ed. Manuel García Blanco/Rafael Pérez de la Dehesa, Madrid, Escelicer, 9 vols., 1967-1971.

14 Miguel de Unamuno, Obras completas, ed. Ricardo Senabre, Madrid, Fundación José Antonio Castro/Turner, 10 vols., 1994-2009. 
embargo, de un banal descriptus con algún error en la puntuación y la acentuación. En este testimonio se omiten algunas palabras para recortar el diálogo final ${ }^{15}$, se registran un par de pequeñas sustituciones ${ }^{16} \mathrm{y}$, sobre todo, se insertan unas correcciones posiblemente $\operatorname{tardías}^{17}$ : variantes que lo convierten en la última versión del relato.

Ahora bien, aunque no sea preciso preferir esta última redacción (es muy ardua la cuestión de las últimas o penúltimas voluntades del autor, y no vamos a abordarla aquí ${ }^{18}$ ), está claro que un editor debería informar al público al menos de la existencia de ese autógrafo; $y$, al margen de cuál sea el texto base escogido para la edición, también sería aconsejable brindar en un aparato al lector especialista las muy pocas variantes que separan la versión impresa del manuscrito que, según parece, quedó encerrado en el archivo unamuniano y no tuvo ninguna circulación.

Este caso de reescritura, caracterizado por la escasa entidad de los retoques, nos viene de perlas para explicar cuándo, a juicio de la filología de autor, disciplina eminentemente pragmática, se vuelve insensata la opción de reproducir de manera integral las diferentes versiones de un texto.

15 No copia este fragmento del texto publicado: “-Si no me vendáis los ojos, no le doy de mamar. / -Sé razonable, María”. Además, poco antes había omitido también un par de palabras ("en" y "aquí") de la versión impresa: “-María -le dijo su hermano con voz trémula tocándole en un hombro,- eres madre, aquí te traen tu niño, que olvidaste en casa al venirte; viene llorando..."; obsérvese que la omisión de "en" sirve para eliminar un caso de leísmo del acusativo femenino.

16 En lugar de "Y luego de reponerse murmurando ¡qué brutos son los hombres! cayó de hinojos ante su padre preguntando...", Unamuno escribe en el autógrafo: "Y luego de reponerse murmuró: ¡qué brutos son los hombres! y cayó de hinojos ante su padre preguntando...”.

17 De "Y al día siguiente, precisamente al día siguiente de la portentosa cura" (versión del relato publicado en los Lunes de "El Imparcial"), el manuscrito, al cabo de una serie de retoques, pasa a "A los pocos días de la portentosa cura[,] no habiendo aún salido de casa la operada".

18 "Se ne conclude che non si tratta di aporie insolubili (sempre l'ultima o sempre la prima), o al contrario di soluzioni tutte egualmente praticabili (in una specie di pirronismo filologico), ma di scelte da operare a seconda dei destinatari del testo, senza tuttavia perdere la sua identità", Paola Italia, Editing Novecento, pp. 39-40. Sobre dicha cuestión, véase "Foro - Le volontà dell'autore (Bologna, 2 maggio 2011). Daniel Ferrer, Claudio Giunta, Cristina Urchueguía e Paola Italia”, Ecdotica, 8, 2011, pp. 97-141. 
En efecto, es muy provechoso aplicar el modelo editorial texto-aparato si las variantes que separan las diferentes redacciones son circunscritas y fácilmente cotejables; en cambio, cuanto mayor sea la distancia entre las versiones conservadas, menores serán las posibilidades de poder reflejar la evolución textual en un aparato ${ }^{19}$. Veamos un par de ejemplos de cómo se podría ofrecer el pasaje más complicado de ese relato [Lámina 1]:

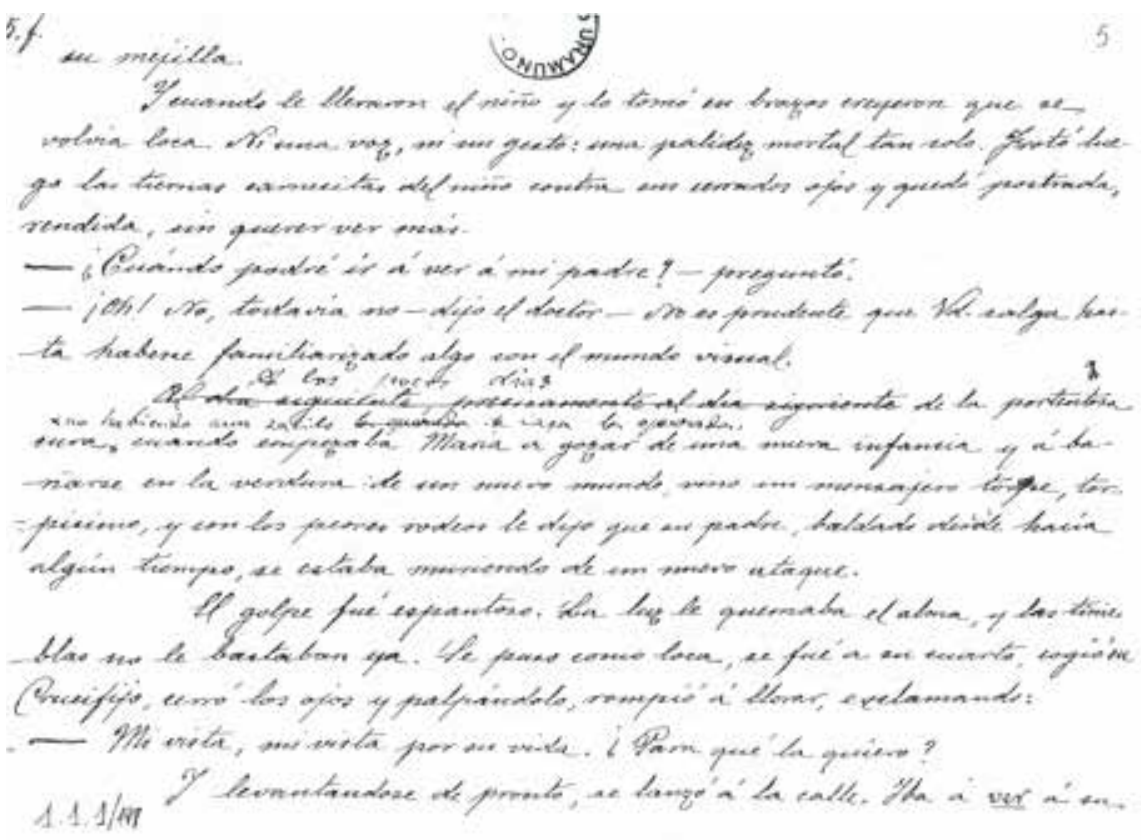

1. Fuente: Casa-Museo Unamuno, Universidad de Salamanca.

1. Texto de la versión impresa con aparato evolutivo que reúne las variantes del autógrafo. Aquí las diferentes fases redaccionales del manuscrito se indican con números volados y las sub-fases con letras voladas; los subrayados evidencian las porciones de texto de una fase que se suprimen en la sucesiva.

19 Véanse Alfredo Stussi, "Filologia d'autore", Introduzione agli studi di flologia italiana, pp. 162-163; y Cesare Segre, "Critique des variantes et critique génétique", Genesis, 7 (1995), p. 39. 
-¿Cuándo podré ir a ver a mi padre?- preguntó.

-¡Oh! No, todavía no -dijo el doctor-. No es prudente que usted salga hasta haberse familiarizado algo con el mundo visual.

Y al día siguiente, precisamente al día siguiente de la portentosa cura, cuando empezaba María a gozar de una nueva infancia y a bañarse en la verdura de un nuevo mundo, vino un mensajero torpe, torpísimo, y con los peores rodeos le dijo que su padre, baldado desde hacía algún tiempo, se estaba muriendo de un nuevo ataque.

$\mathrm{Y}$ al día siguiente, ... portentosa cura] ${ }^{1} \underline{\mathrm{Al}}$ día siguiente, precisamente al día siguiente de la portentosa cura, ${ }^{2} \mathrm{~A}$ los pocos días de la

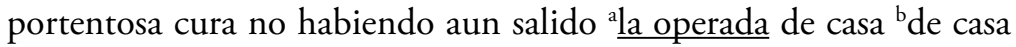
la operada,

2. Texto de la última fase redaccional del autógrafo con aparato genético que reúne las variantes del autógrafo (Ms) y de la redacción impresa (I); las flechas separan las diferentes fases y el subrayado se utiliza como en el ejemplo anterior; la sigla $T$ indica la última fase del manuscrito que se corresponde con el texto crítico.

-¿Cuándo podré ir a ver a mi padre?- preguntó.

-¡Oh! No, todavía no -dijo el doctor-. No es prudente que usted salga hasta haberse familiarizado algo con el mundo visual.

A los pocos días de la portentosa cura[,] no habiendo aún salido de casa la operada, cuando empezaba María a gozar de una nueva infancia y a bańarse en la verdura de un nuevo mundo, vino un mensajero torpe, torpísimo, y con los peores rodeos le dijo que su padre, baldado desde hacía algún tiempo, se estaba muriendo de un nuevo ataque.

A los pocos días ... de casa la operada,] Y al día siguiente, precisamente al día siguiente de la portentosa cura, $\mathbf{I} \mid \underline{\text { Al día siguiente, pre- }}$

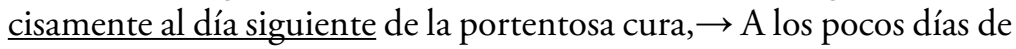
la portentosa cura no habiendo aun salido la operada de casa $\rightarrow$ T Ms

No sabemos exactamente por qué razón Unamuno no volvió a publicar este cuento en un volumen; pero acaso influyó la decisión de aprovechar 
esta misma fábula para una pieza teatral. Ahora bien, el drama La venda presenta un problema ecdótico análogo al que plantea el relato homónimo, si bien las responsabilidades de los editores tienen que ver, en este caso, más con la collatio que con la recensio.

Curiosamente, antes de escribir el relato que vería la luz en Los Lunes de "El Imparcial", Unamuno ya había barajado la posibilidad de redactar una pieza que debía titularse La ciega, de la que se conservan unos borradores en la Casa-Museo ${ }^{20}$; pero estos bocetos tienen poco o nada que ver con la obra teatral de La venda que se publicó mucho más tarde, el 19 de junio de 1913, en la colección de "El Libro Popular". De dicha pieza dramática no se conserva solo la versión impresa del ' 13 -que es la que han seguido García Blanco y todos los editores sucesivos-, sino también "un manuscrito autógrafo que forma[ba] parte de la espléndida colección teatral de don Arturo Sedò" ${ }^{21}$ y que se custodia en el Instituto del Teatro de Barcelona (sign. 83117). García Blanco no reparó en las numerosas variantes redaccionales que separan el autógrafo del texto publicado en 1913 y, sobre todo, no se preguntó si el manuscrito transmitía una redacción anterior o posterior a la impresa. Paulino Ayuso, que volvió a editar la pieza en 1987 para Castalia, ensayó una ordenación cronológica de los testimonios del cuento y del drama: "Conservamos, pues, y por orden cronológico, unas cuatro versiones: los borradores [sc. los bocetos del drama La Ciega], [...] el cuento impreso, el manuscrito [sc. el autógrafo del Instituto del Teatro barcelonés], el texto dramático editado" ${ }^{22}$. Y, además, llevó a cabo un cotejo somero entre aquellos que consideraba los dos últimos estadios del proceso redaccional, ya que señala las variantes del manuscrito que perteneció a Sedò en nota; pero, desafortunadamente, no comprendió que algunas correcciones de dicho testimonio no son de Unamuno, sino de una segunda mano que todavía no he logrado identificar ${ }^{23}$, aunque debía

20 Dio noticia de estos borradores (CMU, 67/86 y 70/10) Manuel García Blanco en el "Prólogo" a Miguel de Unamuno, Teatro completo, Madrid, Aguilar, 1959, p. 69.

21 Ibidem.

22 José Paulino Ayuso, "Introducción", en Miguel de Unamuno, La esfinge. La venda. Fedra, Madrid, Castalia, 1987, p. 50.

23 Esta segunda mano elimina algunos fragmentos y sustituye numerosas lecciones: "Un bastón" con "Un cayado" en la p. 2, "Eugenia" con "Engracia" en la p. 4, "Ha visto a mi señorita, Señora Eugenia?" con "Ha visto a María, Eugenia?" en la p. 5, "llegó un médico que dijo que se le podía opera[r] para devolverle la vista, y la operó 
pertenecer a uno de los directores de las compañías que representaron el drama (con este signo "\#”, por ejemplo, dicha mano indica el momento en el cual tiene que salir a escena un determinado personaje, e inserta glosas del estilo "Prudencia”, “ojo” etc.) [Lámina 2].

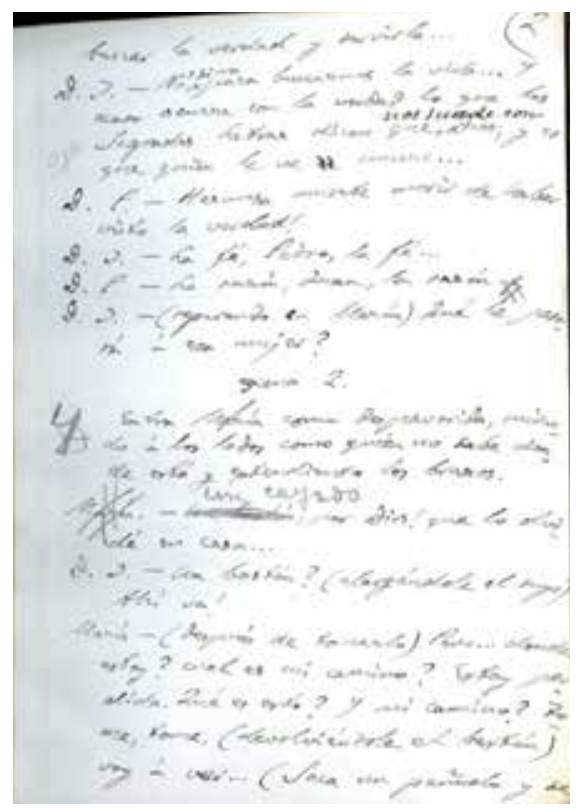

2. Fuente: Centre de Documentació i Museu de les Arts Escèniques. Institut del Teatre.

El hecho de que el autógrafo lleve huellas de su adaptación escénica no es determinante para descifrar su relación con la otra redacción, porque La venda se representó tanto antes como después de su publicación en "El Libro Popular"24. Se leyó el 10 de febrero de 1911 en el Teatrillo de los

y se la devolvió y ahora ve ya" con "llegó un sabio y dijo que daría vista y ahora ve ya" en la p. 6, "No se cura con caldos" con "No se cura con esto" en la p. 12, etc.

24 García Blanco, que desconocía esas primeras representaciones, sostenía que la pieza se había estrenado varios años después de su publicación; véase Manuel García Blanco, "Prólogo", en M. de Unamuno, Teatro completo, pp. 66-69; "Introducción", en Miguel de Unamuno, Obras completas, Madrid, Escelicer, t. V, 1968, pp. 46-48. 
Hermanos Millares en Las Palmas ${ }^{25}$ y tuvo luego que esperar otro par de años para llegar a estrenarse, en mayo de 1913, en el Teatro Español de Madrid $^{26}$. Más tarde, en enero de 1921, subió a las tablas por tercera vez: fueron las del Teatro Bretón de Salamanca; y el periódico salmantino $E l$ Adelanto celebró este regreso publicando los primeros dos cuadros de la pieza (el 8 y el 10 de enero): se trata, y este es un indicio interesante, de la misma redacción publicada en el '13. Finalmente, unos meses después $L a$ venda volvió al Teatro Español gracias a la compañía de Francisco Fuentes cosechando un notable éxito, conforme se colige de la reseña que publicó Francisco de Cossío en El Norte de Castilla el 13 de junio de 1921.

Las variantes de autor presentes en el manuscrito que fue a parar a la colección Sedò me inducen a poner en tela de juicio la secuencia imaginada por Paulino Ayuso y a suponer, en cambio, que este testimonio transmite una versión posterior a la impresa. En efecto, en varios lugares del autógrafo Unamuno reprodujo o iba a reproducir la misma lección de la versión impresa para luego modificarla. Me limitaré a unos cuantos ejemplos, en los cuales transcribiré antes la versión impresa I (según la edición de Paulino Ayuso) y a continuación la del autógrafo Ms con el auxilio de algunos signos diacríticos:

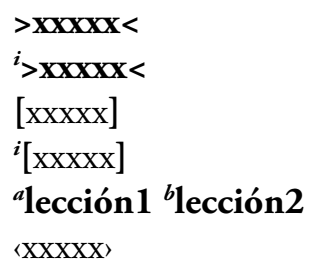

Tachadura posiblemente tardia

Tachadura inmediata

Añadido posiblemente tardio

Añadido inmediato

Sustitución posiblemente tardia

Integración editorial

1) Ms pasa de "se muere", lección presente en $\mathbf{I}$, a "muere".

Don JuAn. ¡Qué atrocidad! Tal vez nos sucede con la verdad lo que, según las Sagradas Letras, nos sucede con Dios, y es que quien le ve se muere... (Paulino Ayuso, p. 158)

D. J. - No, [sino] para buscarnos la vida... Y acaso ocurra con la

25 Véase Carmen Yolanda Arencibia Santana, "Galdós y Unamuno en la misma hoguera”, Anales galdosianos, 42-43 (2007-2008), pp. 31-46.

26 Véanse la reseña sin firma "Notas teatrales", $A B C$, 26 de mayo de 1913, p. 18; y la de Caramanchel, titulada "Los estrenos en Madrid", en el periódico mallorquí $\mathrm{La}$ Región, 29 de mayo de 1913, p. 1. 
verdad lo que las Sagradas Letras dicen que ${ }^{i}$ [nos sucede con] Dios; y es que quien le ve $>$ se $<$ muere. (Ms, p. 2)

2) Ms, nada más copiar la misma acotación presente en I, la modifica.

Don Pedro. (a Don Juan, aparte) Parece loca. (Paulino Ayuso, p. 159)

${ }^{i}>$ D. P. $-($ á Don Juan aparte $)<$

D. P. - (á Don Juan mientras se señala la frente con el dedo) Acaso... (Ms, p. 3)

3) Ms empieza a escribir la lección de I (“y jamás se pierde”) y acto seguido la cambia: "sin jamás perderse".

Señora Eugenia. Ciega, sí. Recorre así, con su bastón, la ciudad toda y jamás se pierde. [...] (Paulino Ayuso, p. 160)

$S^{a}$ Eug. - Ciega, sí. Recorre con su bastón, como la ven, la ciudad toda ${ }^{i}>\mathbf{y}<$ sin jamás perderse en ella. [...] (Ms, p. 4)

4) Nueva sustitución inmediata de Ms, que reemplaza "llenó" (I) con "hartó".

CRIADA. ¿Al abuelo? ¡Ella no! Al que lo han llevado a que lo vea es al niño. Y cuando volvió le llenó de besos [...] (Paulino Ayuso, p. 164) la cr. - Al abuelo? Ella no. Al que lo han llevado á que lo vea es al niño. Y cuando lo volvieron á traer ella le $>$ llen ‘ó $<$ hartó de besos [...] (Ms, p. 10)

5) Aunque la frase cambie significativamente en las dos versiones, es interesante que Ms sustituya "tiene", presente también en $\mathbf{I}$, con "tenga".

Marta. ¿Hoy? ¡Lo dudo! Tiene mucho que hacer, tarea para unos días. (Paulino Ayuso, p. 168)

$\mathrm{Mt}-$ Hoy? lo dudo. Creo que ${ }^{a}$ tiene ${ }^{b}$ tenga tarea para días. (Ms, p. 14)

6) Otra sustitución presuntamente tardía en la cual Ms modifica la primigenia lección coincidente con $\mathbf{I}$.

José. Sí, con el silencio se la conjura. (Paulino Ayuso, p. 174)

J. - Sí, con ${ }^{a}$ el silencio ${ }^{b}$ no mentarla se la conjura. (Ms, p. 22) 
En definitiva, en las dos tradiciones que acabo de delinear de esta forma tan superficial, un filólogo sin duda escogería una versión (o la redacción impresa o la última fase de los autógrafos), confinando en un aparato evolutivo o genético las variantes de la otra. Y si por un casual decidiera preparar la edición del manuscrito Sedò -lo cual sería oportuno no solo porque en mi opinión, como he dicho, parece transmitir una versión sucesiva respecto a la de 1913, sino también porque esta redacción no se ha vuelto a publicar desde $1939^{27}$, entonces podrían acompañar al texto un aparato genético que explique la evolución redaccional desde el impreso al manuscrito y una sección de notas que, entre otras cosas, aclare las intervenciones de la segunda mano. De este modo:

\section{Escena 4 \\ Dichos y la $\mathrm{S}^{\mathrm{a}}$ Eugenia}

${ }^{1}$ D. P. - (a la señora Eugenia que pasa, indicándole a lo lejos a María) Loca, ‘ $>$ eh?

${ }^{2} \mathrm{~S}^{\mathrm{ra}}$ Eug. - $\dot{\iota}$ Loca? no; ciega.

${ }^{3}$ D. P. $-\langle\dot{\jmath}$ Ciega?

${ }^{4} \mathrm{~S}{ }^{\text {ra }}$ Eug. - Ciega, sí. Recorre con su bastón, como la ven, la ciudad toda sin jamás perderse en ella. Conoce a maravilla sus callejas y rincones todos. Se casó hará cosa de un año y casi a diario va a ver a su padre, muy viejecito ya, que habita en un barrio de las afueras. Pero $\langle\dot{\jmath}$ es que no son de la ciudad ustedes?

\section{Escena 4 / Dichos y la $\mathrm{S}^{\text {ra }}$ Eugenia] falta en $\mathbf{I}$}

1. (a la señora Eugenia que pasa ... ‘ $\dot{\iota}$ Loca, eh?] (A la señora Eugenia, que pasa) Loca, ¿no es verdad? I

3. ‘`Ciega?] Ciega. I (probable error)

4. Reco rre] Recorre así I como la ven, la ciudad toda] la ciudad toda $\mathbf{I}$ sin jamás perderse en ella.] y jamas se pierde. I $\|>\mathbf{y}<\sin$ jamás perderse en ella. Ms (variante inmediata; la " $y$ " tachada sugiere que el autor iba a escribir las mismas palabras de I) a maravilla] falta en I a diario] todos los días I muy

27 Apareció en el periódico Domingo, III, n. 139, 15-X-1939, p. 3; cfr. José Paulino Ayuso, "Introducción", en Miguel de Unamuno, La esfinge. La venda. Fedra, Madrid, Castalia, 1987, p. 49, nota 68. 
viejecito ya,] falta en I habita] vive I

no son de la ciudad ustedes?] ustedes no son de la ciudad? I

\section{Notas}

Dichos y la Sra Eugenia. La segunda mano tacha "Eugenia" y lo sustituye con "Engracia" porque el mismo autor, en el elenco incial de las dramatis personae, había cambiado el nombre a este personaje.

\section{El autógrafo aCÉfalo de "Del Sentimiento trágico de la vida”}

Ya me he ocupado en otras ocasiones de algunos proyectos unamunianos reciclados en el más importante texto filosófico del que fue Rector de Salamanca; y hasta he dado a conocer, en colaboración con Bresadola, el plan de dicha obra ${ }^{28}$. Ahora voy a examinar el autógrafo de los capítulos VIII-XII de Del sentimiento trágico de la vida conservado en la Vaticana de Roma (sign.: Autografi Paolo VI, 28 ter), cuya existencia creo que se le ha escapado hasta ahora a todos los estudiosos del maestro vasco, aunque ya diera noticia de este manuscrito el catálogo Testimoni dello spirito. Mostra di autografi offerti a Paolo VI nell'ottantesimo anno per la Biblioteca Apostolica Vaticana (1979) ${ }^{29}$. Duilio Susmel donó a Paolo VI este manuscrito junto con una carta autógrafa de Unamuno a Odoardo Campa, primo de Gilberto Beccari, y otros materiales relacionados con don Miguel procedentes del archivo del mismo Campa ${ }^{30}$.

28 Miguel de Unamuno, Meditaciones evangélicas, ed. P. Tanganelli, Salamanca, Diputación de Salamanca, 2006; Paolo Tanganelli y Andrea Bresadola, "El Plan de Del sentimiento trágico", Cuadernos de la Cátedra Miguel de Unamuno, 44 (2007), pp. 143-200; Paolo Tanganelli, "Del erostratismo al amor de Dios: en torno al avantexto de Del sentimiento trágico de la vida", en Miguel de Unamuno. Estudios sobre su obra. II, Salamanca, Universidad de Salamanca, 2005, pp. 175-194. Giulia Giorgi, "Estudio y edición de $A$ la juventud hispana: un proyecto clave en el proceso creativo de Del sentimiento trágico de la vida", Cuadernos de la cátedra Miguel de Unamuno, [en prensa], nos proporciona una tesela fundamental para reconstruir el mosaico de los proyectos confluidos en Del sentimiento trágico.

29 Véase Testimoni dello spirito. Mostra di autografi offerti a Paolo VI nell'ottantesimo anno per la Biblioteca Apostolica Vaticana, Città del Vaticano, LEV, 1979, p. 372.

$30 \mathrm{El}$ fondo Campa donado por Susmel se ha dividido en tres carpetas: 1) la primera contiene el autógrafo de Del sentimiento trágico (sign. Autogr. Paolo.VI.28.ter); 2) 
Las cuartillas recuperadas, de las cuales quisiera ofrecer en los próximos años una edición con doble aparato, genético y evolutivo, debieron formar parte del manuscrito que Unamuno envió a Gilberto Beccari para que vertiera su texto al italiano. Como es sabido, Beccari tradujo, entre 1913 y 1914, los primeros seis capítulos para la colección "Biblioteca di Filosofia Contemporanea” de la Libreria Editrice Milanese, dirigida por su primo Odoardo Campa, con el cual firmaría diez años más tarde la versión italiana de la segunda parte de Del sentimiento trágico de la vida (La Voce, Florencia, 1924) ${ }^{31}$.

Para citar los fragmentos del manuscrito se utilizarán los siguientes signos diacríticos:

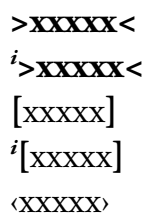

-lección1> lección2
Supresión posiblemente tardia.

Supresión inmediata.

Añadido presuntamente tardio.

Añadido inmediato.

Integración editorial.

Sustitución inmediata: la flecha bicolor equivale a "se reemplaza en seguida con"; es posible que se den varias sustituciones inmediatas concatenadas.

alección1 blección2
Susitución presuntamente tardía.

en la segunda se custodia la carta autógrafa de Unamuno que lleva la fecha del 3 de dicembre de 1912, junto con varios recortes de periódicos sobre el autor vasco recopilados por el mismo Campa (Autogr. Paolo.VI.28.n.597 ff. 0001-0003); 3) en la tercera se hallan materiales muy variados, entre los cuales cabe destacar unos apuntes autógrafos de Campa, las pruebas de los últimos dos capítulos de una traducción italiana de Del sentimiento trágico, una carta de Fernando de Unamuno Lizarraga, tres cartas de Manuel García Blanco a Odoardo Campa, así como las copias de las misivas que remitió el primo de Beccari al editor de las Obras Completas (Autogr. Paolo.VI.6.n.86).

31 En la copia de una carta de Campa a García Blanco del 31-X-1960 (Autogr. Paolo. VI.6.n.86, ff. 102-103), aquel reivindica ser el único traductor de la segunda parte en un español bastante inseguro: "De esto [sic] trabajo [sc. la traducción de la primera parte de Del sentimiento trágico] dejé el mérito a mi primo, dado que por su medio habíamos alcanzado el M.S. Pero constante fue mi colaboración con mi primo. Vino la guerra, el destino llevó en [sic] Rusia adonde permanecí cinco ańos. Regresado en [sic] Florencia tuve que afrontar yo solo la segunda parte del SENTIMIENTO. [...] Beccari, empeñado en otros trabajos, declinó francamente toda colaboración". 
El autógrafo de la Vaticana se indicará con la sigla Ms, remitiendo a las cuartillas numeradas por el autor (con la abreviación c./cc.). Las dos primeras ediciones se citarán, sin especificar las páginas correspondientes, con las siglas $\mathbf{R}$ para la de La España Moderna (que publicó los doce capítulos de diciembre 1911 a diciembre 1912) y V para la de la editorial Renacimiento (que tuvo que editarse en el '13, aunque en el catálogo de Palau se feche en 1912).

\section{I. Descripción}

El testimonio comprende 461 cuartillas, por regla general escritas por una cara, que presentan una doble numeración: en el ángulo superior derecho, la del mismo autor, quien numeró las cuartillas de cada artículo; en el ángulo inferior derecho, una numeración moderna de todas las cuartillas desde la n. 1 hasta la n. 461. Se trata de la parte final del cap. VIII y de los cuatro capítulos siguientes (del IX al XII) de Del sentimiento trágico de la vida; pero algunas cuartillas del cap. VIII se han traspapelado y colocado erróneamente después del cap. XII. Los capítulos IX, X y XI van encabezados por hojitas de forma irregular, sin numeración, que deben ser los restos de los sobres que contenían las cuartillas de dichos artículos: en el centro de estas hojitas destaca el número romano del capítulo correspondiente, trazado con lápiz, mientras que en el ángulo superior derecho se indica, en números arábigos y con pluma, la cantidad de cuartillas que forman el capítulo.

La foliación unamuniana de las cuartillas se puso primero con lápiz y en un segundo momento con tinta para facilitar la inserción de los añadidos más largos; así que las huellas de la primitiva numeración con lápiz permite reconstruir la estratificación de los diferentes segmentos textuales que forman cada capítulo.

En la descripción del contenido se hace referencia a la foliación moderna:

ff. 1-40 - Cuartillas 53-92 del cap. VIII según la numeración unamuniana; el autor utilizó también la vuelta de las siguientes cuartillas: f. 8 (cuartilla 60); f. 32 (cuartilla 84); f. 34 (cuartilla 86); f. 38 (cuartilla 90). 
f. [40bis] - Hojita con el número "IX"; en el ángulo superior derecho, con letra más pequeña: " 89 ".

ff. 41-129 - Cuartillas 1-89 del cap. IX según la numeración unamuniana.

f. [129bis] - Hojita con el número "X"; en el ángulo superior derecho, con letra más pequeña: "121"; hay algunos signos tachados que no logro descifrar y una palabra, trazada por una mano diferente, que podría ser "Piestelle".

ff. 130-250 - Cuartillas 1-121 del cap. X según la numeración unamuniana; el autor utilizó también el reverso de las siguientes cuartillas: f. 175 (cuartilla 46), f. 186 (cuartilla 57), f. 211 (cuartilla 82), f. 213 (cuartilla 84), f. 221 (cuartilla 92).

f. [250bis] - Hojita con el número "XI"; en el ángulo superior derecho, con letra más pequeña: “105” (repetido más abajo con lápiz); otra mano escribió también: "Mss Unamuno".

ff. 251-355 - Cuartillas 1-105 del cap. XI según la numeración unamuniana; el autor utilizó también el reverso de las siguientes cuartillas: f. 266 (cuartilla 16), f. 272 (cuartilla 22), f. 301 (cuartilla 51), f. 326 (cuartilla 76). La numeración moderna demuestra que se descolocó la cuartilla 63 (f. 316), que no figura entre la 62 (f. 312) y la 64 (f. 313).

ff. 356-455 - Cuartillas 1-98 del cap. XII según la numeración unamuniana, que es bastante irregular: entre las cuartillas 1 (f. 356) y 2 (f. 358), aparece, en el f. 357, la cuartilla 1bis; y entre las cuartillas 6 (f. 362) y 7 (f. 364), se encuentra una sin número (f. 363). Unamuno utilizó también el reverso de las siguientes cuartillas: f. 371 (cuartilla 14), f. 396 (cuartilla 39), f. 425 (cuartilla 68), f. 437 (cuartilla 80), f. 440 (cuartilla 83).

ff. 456-461 - Cuartillas 47-52 del cap. VIII según la numeración unamuniana; el autor utilizó también el reverso de las siguientes cuartillas: f. 456 (cuartilla 47), f. 458 (cuartilla 49).

El hecho de que la firma unamuniana luzca al final de cada ensayo o capítulo sugiere que precisamente estas cuartillas -antes de viajar a Italia para que las tradujera Beccari- pudieron haberse enviado a la revista de Lázaro Galdiano. 


\section{2. "Usus scribendi" unamuniano}

La preparación del autógrafo fue bastante apresurada, como revelan los numerosos lapsus calami ${ }^{32}$-por lo general, de fácil enmienda-, además de la puntuación descuidada y carente principalmente de comas. Si fueron estas las mismas cuartillas que se entregaron a Lázaro Galdiano, sería entonces necesario conjeturar que la revisión de la puntuación se confió a los correctores de La España Moderna y a la sucesiva revisión unamuniana de las pruebas ${ }^{33}$.

El texto de la revista presenta, respecto al manuscrito, algunas pequeñas variantes atribuibles al autor que impiden descartar del todo la posibilidad de que existiera una versión intermedia manuscrita entre $\mathbf{M s}$ y $\mathbf{R}$, en la cual el polígrafo bilbaíno introdujera justo esos pequeños retoques (y quizás revisara ya la puntuación); pero yo considero bastante más probable que Unamuno, según su costumbre, insertara dichas variantes en las mismas galeradas.

Entre las características más significativas de la lengua de Ms, cabe destacar un par de casos de leísmo del acusativo femenino que obviamente derivan del sustrato dialectal bilbaíno: incidencia que marca el sistema pronominal de don Miguel durante toda su vida y que ya he señalado en el autógrafo de la novela Nuevo Mundo (1895-96) ${ }^{34}$. Dichas 'efraccio-

32 “...l'autografia non garantisce la corrispondenza all' «originale $=$ testo interiore dell'autore» a causa della possibile presenza in ogni autografo di segmenti involontariamente non corrispondenti al testo interiore, che l'autore avrebbe senz'altro corretto se avesse esaminato il suo scritto con maggiore attenzione (errori pertanto da distinguere accuratamente da quelli 'oggettivi' dovuti ad ignoranza o incapacità dell'autore, e che quindi sono autentici, corrispondendo alla sua intenzione)", Elio Montanari, La critica del testo secondo Paul Maas, Firenze, Sismel - Edizioni del Galluzzo, 2003, p. 14. Acerca de los errores de autor, puede verse Michael D. Reeve, "Errori in autografi", Manuscripts and Methods. Essays on Editing and Transmission, Roma, Edizioni di Storia e Letteratura, 2011, pp. 3-23.

33 También en otros casos sabemos que las ediciones supuestamente controladas por Unamuno no respetan su voluntad; véase Norbert von Prellwitz, "Le edizioni dei sonetti di Unamuno e la volontà dell'autore", Ecdotica e testi ispanici. Atti del Convegno di Verona, 18-19-20 giugno 1981, Verona, Grafiche Fiorini, 1982, pp. 125-134. 34 Véase Paolo Tanganelli, "Los borradores unamunianos (algunas instrucciones para el uso)", en Bénédicte Vauthier - Jimena Gamba Corradine (coords.), Crítica genética y edición de manuscritos hispánicos contemporáneos. Aportaciones a 
nes' del sistema pronominal etimológico ("compadecerles" en lugar de "compadecerlas" y "le llaman" en lugar de "la llaman"), que contribuyen a configurar el idiolecto unamuniano, se cuelan en $\mathbf{R}$ y se transmiten a $\mathbf{V}$, manteniéndose - a mi juicio muy oportunamente- también en la reciente edición de Orringer ${ }^{35}$ :

En Dios vive todo y en su padecimiento padece todo y al amar a Dios amamos en Él a las criaturas, así como al amar a las criaturas y compadecerles amamos en ellas y compadecemos a Dios. [Ms, IX, cc. 72-73]

Y a la pasión que se expresa por esta retórica le llaman egotismo los de la ciencia ética, y el •egotismo ese $\supset$ tal egotismo es el único verdadero remedio del egoísmo, de la avaricia espiritual, del vicio de conservarse y ahorrarse y no de tratar de perennizarse dándose. [Ms, XI, c. 74]

Otras peculiaridades gráficas del manuscrito son la presencia de algunas formas arcaizantes, como el verbo absorver y el sustantivo mobilidad, además del uso antiacademicista de la $j$ en lugar de la $g$ para la fricativa velar sorda, como en este caso:

$\mathrm{Y}$ no $\bullet$ he $>$ ha de pasar por alto el lector que he estado operando sobre mí mismo; que ha sido este un trabajo de auto-cirujía y sin más anestésico que el trabajo mismo. [Ms, XII, f. 68]

auto-cirujía $\mathbf{M s}$ ] auto-cirugía $\mathbf{R}$ V

\section{Las variantes de aUtor EN $\mathbf{R}$}

El texto publicado en La España moderna introdujo una serie de errores mecánicos que deturparían toda la tradición impresa sucesiva (vid. infra

una poética de transicion entre estados, Salamanca, Universidad de Salamanca, pp. 73-96 (pp. 81-83).

35 Miguel de Unamuno, Del sentimiento trágico de la vida en los hombres y en los pueblos y Tratado del amor de Dios, ed. Nelson Orringer, Madrid, Tecnos, 2005. Orringer, al no adoptar un criterio claro de fijación textual para elegir entre las variantes de $\mathbf{R}$ y $\mathbf{V}$, contamina los dos estadios redaccionales. 
\$6.), ya que Unamuno no detectó estas corruptelas ni siquiera cuando preparó la edición de $\mathbf{V}$ a partir de $\mathbf{R}$. Pero, al lado de estos errores indudables, la versión de la revista presenta también numerosas variantes con respecto a Ms: de la mayoría de estas innovaciones 'aceptables' no es posible establecer si se deben a la revisión del autor o más bien fueron insertadas en fase de composición o corrección tipográfica del texto por otros sujetos; existe, sin embargo, un reducido grupo de lugares de $\mathbf{R}$ donde parece segura la intervención autorial ${ }^{36}$. Se trata, sobre todo, de pequeños añadidos, como la inserción de "y me estruja” en este fragmento:

Creo en Dios como creo en mis amigos, por sentir el aliento de su carińo y su mano invisible e intangible que me trae y me lleva, por tener íntima conciencia de una providencia particular y de una Mente Universal que me traza mi propio destino. [Ms, IX, c. 27]

me lleva Ms] me lleva y me estruja $\mathbf{R} \mathbf{V}$

Mente Universal Ms R] mente universal V

O del sintagma "su hermano" en este otro:

Y si Caín no hubiese matado a Abel habría acaso muerto a manos de este. [Ms, XI, c. 57]

a Abel $\mathbf{M s}$ ] a su hermano Abel, $\mathbf{R}$ V

Asimismo, considero que se debería atribuir al mismo autor la corrección de "es más divino" con "sería más divino", cuya finalidad es ajustar mejor la traducción de unos versos de Browning (en los cuales se lee "were diviner"):

36 Lucia Bertolini ha llevado a cabo un examen modélico de las variantes autoriales que es posible reconocer dentro la varia lectio de la redacción en vulgar del tractado sobre la pictura escrito por Leon Battista Alberti, al basarse en los hábitos de corrección documentados en otros escritos autógrafos del humanista transalpino; véase Lucia Bertolini, "Discussione delle testimonianze manoscritte", en Leon Battista Alberti De pictura [redazione volgare], Florencia, Polistampa [Edizione Nazionale delle Opere di Leon Battista Alberti], 2011, pp. 79-162 (136-162). 
For the loving worm within its clod,

Were diviner than a loveless god

Amid his worlds, I will dare to say.

- "El gusano que ama en su terrón $>$ "Me atreveré a decir que el gusano que ama en su terrón es más divino que un dios sin amor entre sus mundos" dice Roberto Browning... [Ms, VIII, c. 83] $\operatorname{god}$ Ms R] God V

es más divino $\mathbf{M s}$ ] sería más divino $\mathbf{R} \mathbf{V}$

Y la mano unamuniana parece responsable asimismo de otras pequeñas sustituciones, como, por ejemplo, las siguientes:

Pero tuvo su segunda parte porque ese Fausto era el Fausto anecdótico y no el categórico de Goethe, y volvió a entregarse a la Cultura, a Helena, y a engendrar en ella a Euforión acabando todo con aquello del eterno-femenino entre coros místicos. [Ms, XII, cc. 10-11]

su segunda parte porque ese Fausto $\mathbf{M s}$ ] esa segunda parte, porque aquel otro Fausto $\mathbf{R}$ V

Wells, en su libro Anticipations nos dice que "los hombres activos y capaces de toda clase de profesiones religiosas de hoy en día tienden en la práctica a no tener para nada en cuenta (to disregard ... altogether) la cuestión de la inmortalidad." Y es por lo que las profesiones religiosas de esos hombres activos y capaces a que Wells se refiere no suelen pasar de ser una mentira y una mentira sus vidas si quieren basarlas sobre religión. [Ms, XI, cc. 16-17]

de profesiones $\mathbf{M s}$ ] de confesiones $\mathbf{R} \mathbf{V}$

las profesiones $\mathbf{M s}$ ] las confesiones $\mathbf{R} \mathbf{V}$

Y así como se cree en Él por amor, puede también creerse por temor y hasta por odio como creía en •el $>$ Él aquel ladrón Vanni Fucci a quien el Dante hace insultar a Dios con torpes gestos desde el Infierno. (Inf. XXV. 1-3) [Ms, IX, cc. 23-24]

insultar a Dios Ms] insultarle R V (variante de autor para evitar la repetición de "Dios")

(Inf. XXV. 1-3) Ms] (Inf. XXV, 1. 3.) R (Inf. XXV, 1, 3). V (evidente error de composición tipográfica: la numeración de la Commedia en $\mathbf{R} y \mathbf{V}$ carece de sentido, ya que Unamuno se refiere al terceto inicial del canto XXV del "Infierno") 
Si bien, como apuntaba, hay muchas variantes en $\mathbf{R}$ que no se pueden juzgar con certeza de la pluma unamuniana ${ }^{37}$, opino que, si se decidiera abordar una edición de la primera edición en revista, se deberían corregir en el texto crítico solo los errores seguros que transmiten los ensayos de La España Moderna -de los que hablaré luego-, conservando en cambio todas esas innovaciones de borrosa paternidad ${ }^{38}$; y obviamente dos aparatos tendrían que acompañar el texto: uno genético, con las variantes de Ms; y otro evolutivo, con las variantes de $\mathbf{V}$ (y de las reediciones sucesivas, caso de haber evidencia de intervenciones autoriales en ellas).

\section{LAS VARIantes De AUTOR EN $\mathbf{V}$}

La primera edición en volumen de Del sentimiento trágico se preparó utilizando $\mathbf{R}$ como texto base: imagino que el autor vasco envió a la editorial madrileńa Renacimiento unos recortes de los ensayos de La España Moderna con sus correcciones autógrafas. La revisión de $\mathbf{R}$ no fue particularmente esmerada, pues a Unamuno se le escaparon varias alteraciones de su original, y solo logró detectar unos pocos fallos. Subsanó el nombre de la mística de Foligno, sustituyendo el equivocado "Angeles", de R, por "Angela" (con tan mala suerte que el tipógrafo de $\mathbf{V}$ cometió luego una errata precisamente en la composición del topónimo italiano: "Foligo"):

37 En esta categoría figuran muchas omisiones; por ejemplo, $\mathbf{R}$ (y luego, en consecuencia, $\mathbf{V}$ y toda la tradición posterior) omite "nuestro" en un fragmento ("Qué es, en efecto, existir y cuándo decimos que una cosa existe? Existir es ponerse algo de tal modo fuera de nosotros que precediera a nuestra percepción de ello y pueda subsistir fuera nuestro cuando desaparezcamos." [Ms, IX, f. 32]) y "en Él” en otro ("Porque Dios no muere y quien espera en Dios en Él vivirá siempre.” [Ms, IX, f. 44]).

38 Quizás porque el valor que se reconoce a las impresiones en la escuela filológica italiana es mucho más alto que en la tradición anglosajona: "Tra autorità dell'autore e autorità della stampa, nella teoria e nella prassi filologica anglosassone, il peso specifico della prima (quale viene ricostruita dal filologo alias editore critico) è assolutamente preponderante, tanto da giustificare l'emendazione del testo stampato nei luoghi che siano riconosciuti [...] come non dovuti alla volontà dell'autore”, Paola Italia, Editing Novecento, pp. 30-31. 
$\mathrm{Y}$ al fin los de entre aquellos solitarios que nos han contado sus coloquios a solas con Dios han hecho una obra eternizadora, •han〉 se han metido en las almas de los demás. Y ya solo con eso, con que el claustro haya podido darnos un Eckart, un Suso, un Taulero, un Ruisbroquio, un Juan de la Cruz, una Catalina de Siena, una Angela de Foligno, una Teresa de Jesús está justificado el claustro ${ }^{39}$. [Ms, XI, c. 83]

\section{Angela Ms V] Angeles R Foligno Ms R] Foligo V}

Y se dio cuenta, además, de una de las tantas banalizaciones inconscientes del cajista de la revista, que había confundido la difficilior "reputaba" con "respetaba" (error que difícilmente habría podido enmendar de forma conjetural alguien que no fuera el mismo autor ${ }^{40}$ ):

...le decía que conviene obedecer y creer a las determinaciones de los superiores y que reputaba aquel escrito "como una poesía o bien un ensueño, y por tal recíbalo •su> Vuestra Alteza.” [Ms, XII, c. 15] reputaba $\mathbf{M s} \mathbf{V}$ ] respetaba $\mathbf{R}$

Entre los otros retoques de $\mathbf{V}$ atribuibles al autor, algunos son consecuencia del nuevo macrotexto, o sea, del hecho que los artículos recopilados habían de transformarse en un libro; lo cual, en las referencias internas, obligó a sustituir casi siempre "ensayo/s" con "capítulo/s" u "obra", así como a reemplazar "esta misma revista" con "La España Moderna":

${ }^{(*)}$ En mi ensayo “¿Qué es verdad?” publicado en esta misma revista, número >del $\mathbf{1}^{\circ}<$ de marzo de 1906, tomo 207 [Ms, IX, c. 5, nota] en esta misma revista Ms R] en La España Moderna V

39 Aunque figure en los tres testimonios "Taulero", Orringer prefiere, por razones que desconozco, la variante "Tablero".

40 En cambio, no cabe atribuir con seguridad a Unamuno el arreglo ope ingenii de la omisión del verbo "es" en otro punto de este capítulo. Ms trae en la cuartilla 52 del cap. XII: "Y es la tragedia cómica, irracional; es la pasión por la burla y el desprecio". El descuido de $\mathbf{R}$ ("Y Y la tragedia cómica, irracional; es la pasión por la burla y el desprecio") es remediado en $\mathbf{V}$ cambiando simplemente la puntuación ("Y la tragedia cómica, irracional, es la pasión por la burla y el desprecio"). 
No creo excusado remitir al lector una vez más a cuanto dije al final del sexto de estos ensayos, aquel $\bullet$ sobre $>$ titulado "En el fondo del abismo"... [Ms, IX, c. 89]

del sexto de estos ensayos Ms $\mathbf{R}$ ] del sexto capítulo $\mathrm{V}$

Hace ya más de un siglo, en 1804, el más hondo y más intenso de los hijos espirituales del patriarca Rousseau, el más trágico de los sentidores franceses, sin excluir a Pascal, Sénancour, en la carta XC de las que constituyen aquella inmensa monodia de su Obermann escribió las palabras que van como lema a la cabeza de este ensayo... [Ms, XI, cc. 10-11]

$$
\text { ensayo } \mathbf{M s} \mathbf{R} \text { ] capítulo } \mathbf{V}
$$

Todos merecen salvarse, pero merece ante todo y sobre todo la inmortalidad, como en mi anterior ensayo dejé dicho... [Ms, XI, c. 16] ensayo $\mathbf{M s} \mathbf{R}$ ] capítulo $\mathbf{V}$

Y puesto que los españoles somos católicos, sepámoslo o no lo sepamos, queriéndolo o sin quererlo, y aunque alguno de nosotros presuma de racionalista o de ateo, acaso nuestra más honda labor de cultura y lo que vale más que de cultura, de religiosidad -si es que no son lo mismo- es tratar de darnos clara cuenta de ese nuestro catolicismo subconciente, racial o popular. Y esto es lo que he tratado de hacer en estos ensayos. [Ms, XI, c. 101]

racial $\mathbf{M s}$ ] social $\mathbf{R} \mathbf{V}$ (podría tratarse de una variante de autor insertada en $\mathbf{R}$ )

en estos ensayos $\mathbf{M s} \mathbf{R}$ ] en esta obra $\mathrm{V}$

Su muerte y su resurrección. Y hay una filosofía, y hasta una metafísica quijotesca, y una lógica y una ética quijotescas también y una religiosidad -religiosidad católica española- quijotesca. Es la filosofía, es la lógica, es la ética, es $|105|$ la religiosidad que he tratado de esbozar y más de sugerir que de desarrollar en estos ensayos. [Ms, XI, cc. 104-105]

en estos ensayos $\mathbf{M s} \mathbf{R}$ ] en esta obra $\mathbf{V}$

El pulimento que llevó a cabo el antiguo Rector de Salamanca en esta fase de revisión no se puede reconstruir tan fácilmente. Creo que fue su mano la que intervino en una frase interrogativa, que no iba precedida por el 
signo ortográfico “ $¿$ ” ni en el autógrafo ni en la revista, al considerarla demasiado larga:

(¿)Pero dirá alguien que esa que llamamos ley de la gravitación universal u otra cualquiera ley o un principio matemático es una realidad propia e independiente, es un ángel, es algo que tiene conciencia de sí y de los demás, es persona? No, no es más que una idea sin realidad fuera de la mente del que la concibe. [Ms, VIII, cc. 64-65]

demás, es persona? Ms R] demás. ¿Qué es persona? V

Y posiblemente fue de nuevo su pluma la que que limó estos pasajes diferentes:

Creer, vuelvo a decirlo, es dar crédito a uno y se refiere a persona. Digo que sé que hay un animal llamado caballo y que tiene estos y aquellos caracteres porque lo he visto y que creo en la existencia del llamado jirafa u $\bullet$ o[?]ito $>$ ornitorrinco y es que $\bullet$ el $>$ de este o el otro modo, porque creo a los que aseguran haberlo visto. [Ms, IX, cc. 16-17] jirafa Ms] girafa R V

es que $\mathbf{M s}$ ] que es $\mathbf{R}$ que sea $\mathbf{V}$ (en $\mathbf{M s}$ hay un lapsus calami: Unamuno invierte las palabras; $\mathbf{R}$ corrige este desliz y $\mathbf{V}$ introduce una probable variante de autor)

Apenas hay quien sacrificara la vida por mantener que los •dos ang $u$ ulos $>$ tres ángulos de un triángulo valgan dos rectos, pues tal verdad no necesita del sacrificio de nuestra vida, mas en cambio muchos han perdido la vida por mantener su fe religiosa y es que los mártires hacen la fe más aún que fe los mártires. [Ms, IX, cc. 17-18]

que fe Ms R ] que la fe $\mathbf{V}$

Y no es que Don Quijote no comprenda lo que comprende el que así ${ }^{a}$ se $^{b}$ le habla, el que procura resignarse y aceptar la vida y la verdad racionales. [Ms, XII, c. 92]

el que Ms $\mathbf{R}$ ] quien $\mathbf{V}$

Pero en otros puntos no es posible saber si se trata de errores de composición tipográfica o de retoques del polígrafo bilbaíno; es lo que sucede con la omisión de "luego" en este fragmento: 
Una y otra vez durante mi vida heme visto en trance de suspensión sobre el abismo, una y otra vez $\bullet$ me he encon (trado $>$ heme encontrado a en bobre encrucijadas en que se me abría un haz de senderos, tomando uno de los cuales renunciaba a los demás, pues que los caminos de la vida son irrevertibles, y una y otra vez en tales únicos momentos he sentido el empuje de una fuerza conciente, soberana y amorosa. $\mathrm{Y} \bullet$ abrensele a uno luego las〉 ábresele a uno luego la senda del Señor... [Ms, IX, c. 28]

luego Ms R] om. V

O con la sustitución de "cuentan" con "encuentran”, palabras tan parecidas gráficamente, en este otro:

Para estos tales -entre los que se cuentan principalmente los jesuitas- hay dos negocios... [Ms, XI, cc. 46-47]

se cuentan $\mathbf{M s} \mathbf{R}$ ] se encuentran $\mathbf{V}$

No obstante, no puede constituir un obstáculo insuperable esta dificultad de discernimiento entre variantes de copia (porque esto son, al fin y al cabo, las innovaciones del cajista) y variantes de autor; análogamente a lo que he afirmado acerca de una edición de $\mathbf{R}$, vuelvo a sostener que, si se preparara una edición de $\mathbf{V}$-con aparato génetico que recoja las variantes de Ms y $\mathbf{R}$-, todas estas innovaciones aceptables del volumen de la Editorial Renacimiento a mi juicio deberían pasar al texto crítico, del cual habría que desechar tan solo los errores indudables insertados tanto en $\mathbf{R}$ como en el mismo $\mathbf{V}$.

\section{LOS ERRORES DE COPIA DE $\mathbf{R}$}

El autógrafo de la Vaticana nos permite reconocer y enmendar los errores mecánicos que se deslizaron en la serie de ensayos de La España Moderna, y que, por consiguiente, han pasado a la tradición impresa de Del sentimiento trágico de la vida. Con toda probabilidad, estos errores los cometió el cajista; pero no cambiaría su condición ontológica si, por un casual, se descubriera que Unamuno mandó a la revista de Lázaro Galdiano otro manuscrito 
posterior a Ms donde ya figurasen algunos o muchos de estos errores: en efecto, tendríamos que seguir considerándolos todos como unas corruptelas involuntarias, porque el autor, cuando ejerce la función de copista de sí mismo, puede equivocarse igual que cualquier otro amanuense.

Los editores de Del sentimiento trágico han logrado corregir ope ingenii pocos errores de $\mathbf{R}$; por lo que atańe a la parte que es posible cotejar con el autógrafo, en la reciente edición de Orringer se arreglan en el texto tan solo unas pequeñas erratas (en los ejemplos siguientes, la edición mencionada coincide con $\mathbf{M s}$ ):

Es lo bello, lo eterno de las cosas lo que despierta y enciende nuestro amor a ellas o es nuestro amor a las cosas lo que nos revela lo bello, lo eterno de ellas? [Ms, IX, c. 52]

a ellas $\mathbf{M s}$ ] a ella $\mathbf{R} \mathbf{V}$

Así dijo en uno de sus sermones el Rev. Phillips Brooks, obispo que fué de Massachu's'setts, el gran predicador unitariano (v. The Mystery of iniquity and other sermons, sermon XVI) .. [Ms, IX, c. 14] sermon XVI Ms] sermon XII R V

La conciencia, el ansia de más y más y cada vez más, el hambre de eternidad y sed de infinitud, •el apetito $>$ las ganas de Dios, jamás se satisfacen; cada conciencia quiere ser ella y ser todas las demás sin dejar de ser ella, quiere ser Dios. Y la materia, la inconciencia, tiende a ser menos, cada vez menos, a no ser nada, siendo la suya una sed de reposo. [Ms, IX, c. 84]

y cada vez $\mathbf{M s}$ ] cada vez $\mathbf{R} \mathbf{V}$ (variante)

inconciencia $\mathbf{M s}$ ] conciencia $\mathbf{R} \mathbf{V}$

Y entre las armas de vencer hay también la de la paciencia y la resignación apasionadas, llenas de actividad y de anhelo interiores. [Ms, XI, c. 70]

anhelo Ms] anhelos $\mathbf{R} \mathbf{V}$ (variante)

interiores $\mathbf{M s}$ ] anteriores $\mathbf{R} \mathbf{V}$

¿خCómo escapar a una u otra pedantería, a una u otra afectación si el hombre natural no es sino un mito y somos artificiales todos? [Ms, XII, c. 89] pedantería, a una $\mathbf{M s}$ ] pedantería, o una $\mathbf{R} \mathbf{V}$ 
La ayuda que nos brinda Ms es, por lo tanto, sumamente valiosa. Gracias a este documento, por ejemplo, logramos identificar algunos pequeños saltos de igual a igual, quizás el más común de los errores ópticos:

Nuestra pobre e imperfecta concepción de un Dios varón, de un Dios con largas barbas y voz de trueno, de un Dios que impone preceptos y pronuncia sentencias, de un Dios Amo de Casa, Pater familias a la romana, necesitaba compensarse y completarse, y como en el fondo no podemos concebir al Dios personal y vivo no ya por encima de rasgos humanos mas ni aun por encima de rasgos varoniles y menos un Dios neutro o hermafrodita, acudimos a darle un Dios femenino y junto al Dios Padre hemos puesto a la Diosa Madre, a la que perdona siempre porque como mira con amor ciego ve siempre el fondo de la culpa y en ese fondo la justicia única del perdón... [Ms, VIII, cc. 56-57]

varón, de un Dios Ms] om. R V (omissio ex homoiot. de un Dios)

(¿)Cuál es nuestra verdad cordial y antiracional? La de la inmortalidad del alma humana, la de la persistencia sin término alguno de nuestra conciencia, la de la finalidad humana del Universo. [Ms, XI, cc. 9-10]

antiracional $\mathbf{M s}$ ] antirracional $\mathbf{R}$ V

La de la inmortalidad $\mathbf{M s}$ ] La inmortalidad $\mathbf{R} \mathbf{V}$

$\mathrm{Y}$ es porque el sentimiento no ya ético, sino religioso de nuestros sendos oficios, de nuestras respectivas zapaterías, anda muy bajo. [Ms, XI, c. 42]

de nuestros sendos oficios, Ms] om. $\mathbf{R} \mathbf{V}$ (salto de "de nuestros" a "de nuestras")

También otras omisiones son claramente involuntarias, como, por ejemplo, la confusión del estado americano de "Nueva Inglaterra" con "Inglaterra" (trivialización de la que fue responsable sin duda el tipógrafo de $L a$ España Moderna):

Ambas disposiciones [de ánimo] no pueden $\bullet$ excluirse una $>$ estar separadas una de otra por un oceano o una cordillera. En ciertas naciones $\mathrm{y} \bullet \boldsymbol{r e g}$ (iones $>$ tierras como por ejemplo entre los judíos y 
en nuestra propia Nueva Inglaterra se mezclan mucho. Pero en general dividen así al mundo. El Oriente cree en •el crepúscolo del mist $(e r i o$ > $>$ la luz de luna del misterio, el Occidente en el mediodía del hecho científico. [Ms, IX, c. 13]

Nueva Inglaterra Ms] Inglaterra $\mathbf{R} \mathbf{V}$ (error de fácil enmienda, ya que pocas lineas arriba se habla de la ciudad de Boston ${ }^{41}$ )

al mundo Ms] el mundo R V

A veces las pérdidas de texto son menos acusadas y se reducen a corruptelas mínimas que, en la fenomenología de la copía, definiríamos como de posible origen poligenético ${ }^{42}$; verbigracia, en estos fragmentos, la caída de la copulativa "y" o del verbo "es":

Podríamos tal vez morir en una desesperada resignación o en una desesperación resignada entregando nuestra alma al alma de la humanidad, $\bullet$ leg $a$ ando $>$ dejando $>$ legando nuestra labor, la labor que lleva el sello de nuestra persona, si esa humanidada hubiera de legar a su vez su alma a otra alma cuando al cabo se extinga la conciencia sobre esta Tierra de dolor y de ansias. [Ms, VIII, c. 87]

de dolor y de ansias $\mathbf{M s}$ ] de dolor de ansias $\mathbf{R ~ V}$

Adviértase, sin embargo, a $\mathbf{q u e}{ }^{\mathbf{b}}$ como querer creer, es decir, querer crear, no es precisamente creer o crear, aunque sí comienzo de ello.

La fe es, pues, si no potencia creativa, flor de la voluntad y su oficio es crear. [Ms, IX, cc. 20-21]

41 Orringer no corrige el texto, pero señala el error en una nota.

42 En torno a este argumento hay importantes contribuciones del grupo de investigación sobre la Comedia dantesca que capitanea Paolo Trovato: Caterina Brandoli, "Due canoni a confronto: i luoghi di Barbi e lo scrutinio di Petrocchi", en Paolo Trovato (ed.), Nuove prospettive sulla tradizione della "Commedia". Una guida filologico linguistica al poema dantesco, Firenze, Cesati, 2007, pp. 99-214; Elisabetta Tonello, "La tradizione della Commedia secondo Luigi Spagnolo e la sottofamiglia $a_{0}$ (Mart Pal. 319 Triv e altri affini", en Elisabetta Tonello - Paolo Trovato (eds.), Nuove prospettive sulla tradizione della "Commedia". Seconda serie (2008-2013), Padova, Libreriauniversitaria.it, 2013, pp. 72-118; Paolo Trovato, Everything you Always Wanted to Know about Lachmann's Method. A Non-Standard Handbook of Genealogical Textual Criticism in the Age of Post-Structuralism, Cladistics, and CopyText, Padova, Libreriauniversitaria.it, 2014, pp. 109-117. 
aunque sí $\mathbf{M s} \mathbf{R}$ ] aunque sí es $\mathbf{V}$ (probable variante de autor) es crear $\mathbf{M s}$ ] crear $\mathbf{R} \mathbf{V}$

Y del mismo tipo son estas mínimas sustituciones e inserciones:

Ha de ser nuestro mayor esfuerzo el de hacernos insustituibles, el de hacer una verdad práctica el hecho teórico -si es que esto de hecho teórico no envuelve una contradicción in adiecto $\rightarrow$ de que es cada uno de nosotros único e irremplazable, el que no pueda llenar otro el hueco que dejemos al morirnos. [Ms, XI, cc. 24-25]

irremplazable, el que Ms] irreemplazable, de que $\mathbf{R} \mathbf{V}$ (por atracción del anterior "de que")

Y esta hermosura así revelada, esta perpetuación de la momentaneidad, sólo se realiza prácticamente, sólo vive por obra de la caridad. La esperanza en acción es la caridad, así como la belleza en acción es el bien. [Ms, IX, cc. 54-55]

en acción $\mathbf{M s}$ ] en la acción $\mathbf{R} \mathbf{V}$

Y no es que Don Quijote no comprenda lo que comprende el que así ${ }^{a}$ se ${ }^{b}$ le habla, el que procura resignarse y aceptar la vida y la verdad racionales. No, es que sus necesidades afectivas son mayores. (¿)Pedantería? ‘i'Quién sabe...! [Ms, XII, cc. 92-93]

el que $\mathbf{M s} \mathbf{R}$ ] quien $\mathbf{V}$ (probable variante de autor)

afectivas Ms $\mathbf{R}$ ] efectivas $\mathbf{R} \mathbf{V}$ (lectura errónea)

La mayor parte de los errores de $\mathbf{R}$ que estragan la vulgata de Del sentimiento trágico de la vida deriva de una lectura equivocada de algunos grafemas, como en el último trozo citado. En un pasaje del octavo capítulo, donde se alude metafóricamente a Dios como sujeto constructor $y$, a la vez, como ciencia necesaria para construir, $\mathbf{R}$ sustituye errónea y absurdamente "mecánico" con "mecanismo"; de este modo, en el textus receptus se lee que Dios es la ciencia y su producto, mientras que Unamuno tan solo quería repetir que Dios es el "ser conciente constructor" -es decir, el "mecánico"- y su misma sabiduría:

Para explicarnos racionalmente la construcción de una máquina nos basta $\bullet$ la ciencia $>$ conocer la ciencia mecánica del que la cons- 
truyó, pero para comprender que la tal máquina exista, pues que la naturaleza no las hace y sí los hombres, tenemos que suponer un ser conciente constructor. Pero esta segunda parte del razonamiento no es aplicable a Dios $\bullet$. Y no lo es porque el constructor de la máquina no es sino un medio por el que la ciencia mecánica hizo la $>$, aunque se diga que en Él la ciencia mecánica y el mecánico constructores de la máquina son una sola y misma cosa. Esta identificación no es racionalmente sino una petición de principio. [Ms, VIII, cc. 67-68]

mecánico $\mathbf{M s}$ ] mecanismo $\mathbf{R} \mathbf{V}$

Reflejo de una escasa familiaridad con los tecnicismos místicos, que solo puede achacarse al tipógrafo de la revista, es la facilior "vagar" por "vacar", que se ha deslizado dos veces en el penúltimo ensayo de La España Moderna:

...y que no fuese el cuidado de los pies lo que les impidiera vacar a la contemplación de las más altas verdades, les hizo el calzado por amor a ellos y por amor a Dios en ellos, se los hizo por religiosidad. [Ms, XI, c. 41]

$$
\text { vacar } \mathbf{M s} \text { ] vagar } \mathbf{R} \text { V }
$$

La civilización empezó el día en que un hombre sujetando a otro y obligándole a trabajar para los dos pudo vacar a la contemplación del mundo y obligar a su sometido a trabajos de lujo. [Ms, XI, c. 58] vacar Ms] vagar $\mathbf{R}$ V

El elenco de las faciliores de $\mathbf{R}$ parece incluir también "inquietud" por "impiedad", "infando" por "nefando" o "irreductible" por "irremediable":

Y es que así como hay verdad lógica a que se opone el error y verdad moral a que se opone la mentira, hay también verdad estética o verosimilitud a que se opone el disparate y verdad religiosa o de esperanza a que se opone la impiedad de la desesperanza absoluta. [Ms, IX, cc. 36-37]

impiedad Ms] inquietud $\mathbf{R} \mathbf{V}$ (debido también a la grafía de "impiedad" en Ms: la " $p$ " y la secuencia "da" se han trazado de forma poco clara, y pueden confundirse respectivamente con " $q$ " $y$ " $t u$ ") 
Antes de este dábanse en Italia cristianismo y paganismo, o mejor inmortalismo y mortalismo en infando abrazo y contubernio, hasta en las almas de algunos Papas, y era verdad en filosofía lo que en teología no lo era, y todo se arreglaba con la fórmula de salva la fe. [Ms, XII, c. 29]

$$
\text { infando } \mathbf{M s} \text { ] nefando } \mathbf{R} \mathbf{V}
$$

Mi conducta ha de ser la mejor prueba, la prueba moral de mi anhelo supremo y si no acabo de convencerme, dentro de la última e irreductible incertidumbre, de la verdad de lo que espero, es que mi conducta no es bastante pura. [Ms, XI, cc. 7-8] irreductible $\mathbf{M s}$ ] irremediable $\mathbf{R} \mathbf{V}$

Es una banalización también la inversión del orden de las palabras que afecta al título calderoniano "Gustos y disgustos son no más que imaginación”, el cual, a partir de $\mathbf{R}$, se cita en el compendio filosófico unamuniano como "Gustos y disgustos no son más que imaginación":

Pero ya dijo Calderón (Gustos y disgustos son no más que imaginación act. I esc. 4)... [Ms, XII, c. 22]

son no más $\mathbf{M s}$ no son más $\mathbf{R} \mathbf{V}$

Y me pregunto si podría insertarse en esta categoría también la confusión entre "Kultura" y "Cultura" en este pasaje del último capítulo:

Pero ya se sabe, la ${ }^{a}$ cultura ${ }^{b}$ Kultura se compone de ideas y solo de ideas; el hombre no es sino un instrumento en ella. [Ms, XII, c. 32]

Kultura Ms] Cultura R V

ideas; el hombre $\mathbf{M s} \mathbf{R}$ ] ideas y el hombre $\mathbf{V}$

en ella $\mathbf{M s}$ ] de ella $\mathbf{R} \mathbf{V}$

Unamuno escribió inicialmente "cultura" en este punto del autógrafo para modificarlo más tarde en "Kultura". Esta corrección representa entonces una especie de línea de frontera dentro de la "Conclusión" de Del sentimiento trágico de la vida, porque anteriormente figura cuatro veces "Cultura", con mayúscula, mientras que en las páginas siguientes vuelve a aflorar en tres ocasiones más el término paródico "Kultura", con el cual 
el maestro vasco pretendía atacar sobre todo el filosofar neokantiano al que rendía pleitesía Ortega y Gasset. Es posible, en consecuencia, que el cajista aquí no entendiera bien la sustitución unamuniana, al no haberse topado aún con esa extraña grafía, y que decidiera componer el más corriente "Cultura".

Espero que esta primera cala en las corruptelas de $\mathbf{R}$, realizada sin ninguna pretensión de exhaustividad, haya dejado suficientemente patente la posibilidad de enmendar con Ms las ediciones en circulación de la obra filosófica fundamental de don Miguel.

\section{LOS ERRORES DE COPIA DE V}

Como ya he dicho, si tuviera que fijar el texto crítico de $\mathbf{V}$, aceptaría, además de las variantes de autor manifiestas, también todas las lecciones plausibles -es decir, que podrían ser de Unamuno- insertadas en esta fase redaccional, intentando corregir únicamente los errores: tanto los que de $\mathbf{R}$ pasan a $\mathbf{V}$ como las nuevas corruptelas introducidas en el volumen. Desde luego, no siempre resulta fácil reconocer un error seguro, o sea, una innovación que bajo ningún concepto puede atribuirse a la voluntad del autor. Entre los fallos más claros de $\mathbf{V}$, podría indicar los siguientes:

Y es que de sentir la divinidad en todo no puede pasarse, sin riesgo para el sentimiento, a sustantivar[la] y hacer de la Divinidad Dios. Y el Dios aristotélico, el de las pruebas lógicas, no es más que la Divinidad, un concepto y no una persona viva a que se pueda sentir y con la que pueda por el amor comunicarse el hombre. [Ms, VIII, cc. 59-60]

el hombre $\mathbf{M s} \mathbf{R}$ ] al hombre $\mathbf{V}$ (no puede tratarse de una variante de autor, siendo "el hombre" sujeto de "pueda ... comunicarse")

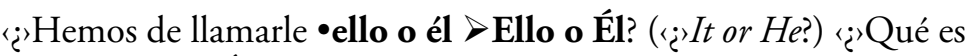
Ello? ‘’'Quién es Él? •Esta ancipacion〉 Estos presentimientos de inmortalidad y de Dios, ‘'‘qué son? Son •meros〉 meras ansias de mi propio corazón •ni oidas ni atendidas $\triangleright$ tomadas por algo vivo fuera de mí? '¿'Son el sonido de mis propios anhelos que resuenan por el vasto vacío de la nada? [Ms, VIII, c. 81] 
tomadas Ms $\mathbf{R}$ ] no tomadas $\mathbf{V}$ (aqui "tomadas por" traduce el inglés "mistaken for")

Y la fe en Dios consiste en crear a Dios y como es Dios el que nos da la fe en Él es Dios el que se está creando •así $>$ a sí mismo de continuo en nosotros. Por lo que dijo San Agustín... [Ms, IX, c. 21] lo que $\mathbf{M s} \mathbf{R}$ ] la que $\mathbf{V}$

Mas a todo esto se me dirá que enseñar que la fe crea su objeto es enseñar que el tal objeto no lo es sino para la fe, que carece de realidad objetiva fuera de la fe misma, como por otra parte sostener que hace falta la fe para contener o para consolar al pueblo es declarar ilusorio el objeto de la fe. [Ms, IX, c. 25]

el objeto Ms R] el objetivo $\mathbf{V}$

Y por lo que hace a que sufra atado a la materia $\bullet$ diran $>$ se me dirá con Plotino (Eneada segunda, IX 7) que el alma del todo no puede estar atada por aquello mismo - que $\bullet$ es el cuerpo $>$ son los cuerpos o la materia - que está por ella atado. [Ms, IX, c. 71] hace a que $\mathbf{M s} \mathbf{R}$ ] hace que $\mathbf{V}$

Hay casos, sin embargo, donde solo se puede sospechar la presencia de un error de composición tipográfica:

Pero ese grado económico no es, en el fondo, sino la incoación del religioso. Lo religioso es lo económico o hedónico trascendente; la religión es una economía o una hedonística trascendental. [Ms, XII, c. 64]

\section{trascendente; la $\mathbf{M s} \mathbf{R}$ ] trascendental. La V}

Es lo que llamó “dolor sabroso" la mística doctora Teresa de Jesús que de amorosos dolores sabía. Es como el que contempla algo hermoso y siente la necesidad de hacer partícipes de ello a los demás. Porque el impulso a la producción, en que consiste la caridad, es obra de amor doloroso. [Ms, IX, c. 75]

amorosos dolores $\mathbf{M s} \mathbf{R}$ ] amores dolorosos $\mathbf{V}$

En ambos ejemplos se puede conjeturar que se haya dado un error por atracción. En el primero, cabe imaginar que la sustitución de "trascen- 
dente" se deba al hecho que en la perícopa memorizada por el tipógrafo estaba incluido también el adjetivo "trascendental". Parece confirmar esta suposición el hecho que Unamuno a continuación, en las tres versiones cotejadas, utiliza de nuevo "trascendente" para expresar el mismo concepto: "Es, pues, la religión una economía trascendente" (Ms, c. 66), "es, en el fondo, un principio [sc. el principio según el cual Dios estaría todo en todo el Universo y en cada uno de los individuos] no lógico, ni estético, ni ético, sino económico trascendente" (Ms, c. 67). En el segundo fragmento, donde $\mathbf{V}$ quiebra el quiasmo "amorosos dolores ... amor doloroso", se podría imaginar que sucedió algo ligeramente diferente respecto a un banal error de memorización; no descartaría, en efecto, que fuera el corrector o el tipógrafo de esta edición quien modificó "amorosos dolores" -calco del "dolor sabroso" teresiano-, considerando más correcto el sucesivo "amor doloroso". En cualquier caso, en ninguno de estos pasajes se puede establecer si se trata de auténticos errores, y por lo tanto conviene que el prudente editor acepte en su texto dichas innovaciones, explicando en una nota sus eventuales dudas.

\section{CONCLUSIÓN PEROGRULLESCA}

Incidentalmente este recorrido podría haber puesto de relieve algunas facetas que diferencian la filología de autor de la critique génétique ${ }^{43}$, aunque no era este su propósito. Para la escuela italiana $-\mathrm{y}$ lo mismo sucede en la alemana- no parece asumible una rígida separación entre antetexto y texto, porque en su enfoque pragmático considera que, en principio, se podría preparar la edición de cualquier redacción ${ }^{44}$. Lo cual significa, entre otras cosas, que no postula necesariamente un único texto editable,

43 En torno a los diferentes modelos de edición de las dos escuelas, siguen siendo fundamentales las páginas de Alfredo Stussi, Introduzione agli studi di filologia italiana, pp. 161-185.

44 "Uno dei «principi fondamentali» affermatisi da tempo tra studiosi tedeschi e italiani è che le varie redazioni d'un'opera hanno, in linea di principio, ugual valore; il che vuol dire che l'editore è, in linea di principio, libero di scegliere l'una o l'altra sulla base del singolo concreto caso in esame", Alfredo Stussi, Introduzione agli studi di filologia italiana, p. 180. 
sino una pluralidad de ellos: en efecto, cada borrador transcrito oportunamente es ya un texto ${ }^{45}$, siendo más bien una ilusión la de poder copiar de forma diplomática los documentos en el dossier genético y dejar para un momento sucesivo su interpretación. Por este motivo la tarea del editor-filólogo consiste en fijar el texto de una determinada fase de elaboración juzgada relevante (y siempre deberá explicar esta decisión), intentando enmarcarlo dentro del entero proceso redaccional a través de los aparatos genético y evolutivo.

He empezado haciendo hincapié en la progresiva especialización de la filología de autor y subrayando la diferencia que media entre sus aparatos y los de la crítica textual. La puesta en claro de esta separación era una premisa necesaria, sobre todo en el ámbito de las letras hispanas, donde en ocasiones se confunden los instrumentos y las finalidades de estas metodologías complementarias o, peor, no se conocen del todo los avances de la filología de autor ${ }^{46}$. Pero ahora, en cambio, ha llegado el momento de volver a enfatizar, algo perogrullescamente como reza el título de este apartado, la raíz que mantiene unidos ambos métodos, o sea, su obvia raigambre filológica. Sobre todo ante tradiciones mixtas como la de $\mathrm{Del}$ sentimiento trágico de la vida, un filólogo debe saber manejarlos, en colaboración e ineludible alianza, para poder reconstruir los avatares de las diferentes redacciones; y así reconocer, entre las líneas de un original, la manifestación de un banal error de copia cometido por el mismo escritor o, aún más importante, divisar, en la estela de Pasquali ${ }^{47}$, variantes de au-

45 Como señala Bénédicte Vauthier en su contribución a este monográfico de Creneida, Rudolf Mahrer ("De la textualité des brouillons. Prolégomènes à un dialogue entre linguistique et génétique des textes", Modèles linguistiques, 59, 2009, pp. 51-70) ha asumido en el ámbito de la critique génétique una postura revolucionaria al plantear justamente la 'textualidad' de los borradores.

46 Por ejemplo, Élida Lois, "De la filología a la genética textual: historia de los conceptos y de las prácticas", en "Archivos". Cómo editar la literatura latinoamericana del siglo $X X$, CRLA-Archivos, s. 1., 2005, pp. 47-83 (pp. 47-57), describe la ruptura originaria de la crítica genética francesa con la tradición filológica, insistiendo esencialmente en lo que diferencia la génétique del método neolachmanniano.

47 Giorgio Pasquali, en el cap. VII ("Edizioni originali e varianti d'autore") de su Storia della tradizione e critica del testo, Florencia, Le Lettere, 2003, pp. 395-465; reproducción facsimilar de la segunda edición de 1952), indicó el camino que permite reconocer variantes de autor en obras de la antigüedad clásica de las que 
tor incluso cuando no dispone de autógrafos o idiógrafos. Tal vez su función sea marcadamente instrumental, como opina Grésillon ${ }^{48}$; pero este humilde trabajo de excavación y criba continúa siendo imprescindible para brindar un fundamento al estudio de cualquier evolución textual.

no sobreviven originales; sus palabras, además de confirmar la insoslayable necesidad de distinguir entre variantes de los copistas y variantes de autor, establecen una interesante relación entre la posibilidad de descubrir correcciones autoriales y la existencia de un mercado librero: "Eliminate felicemente tutte queste innovazioni, antiche e medievali, ci troviamo talvolta ancora di fronte a un resticciolo di varianti, che deve risalire all'autore stesso. Ciò avviene, a quanto vedo, esclusivamente in testi greci o latini dell'ultimo periodo repubblicano o, più spesso, in testi dell'Impero [...] periodo [...] per il quale siamo informati intorno all'esistenza e alle forme di un commercio editoriale o librario..." (p. 395).

48 "...la rigueur philologique permet d'établir le classement chronologique des feuillets à l'intérieur d'un dossier de genése. Mais pour la critique génétique, il s’agit d'un simple outil descriptif et non d'un principe théorique; d'un moyen, non d'une fin", Almuth Grésillon, La mise en oevre. Itinéraires génétiques, CNRS Éditions, Paris, 2008 , p. 27. 